\title{
Composição epistemológica da comunicação comunitária: o conceito propositivo de cidadania para a postura do profissional de Relações Públicas
}

\section{Epistemological composition of communitarian communication: the propositional concept of citizenship for the conduct of Public Relations professionals.}

\author{
Alana Nogueira Volpato'; Daniel de Oliveira Figueiredo ${ }^{2}$
}

\begin{abstract}
Resumo
Ao identificar a pluralidade de sentidos contidos em um mesmo conceito e mostrar que essa polifonia é a expressão das diferenças sociais, políticas e ideológicas na realidade concreta, é preciso esclarecer a historicidade das palavras e de seu uso em estudos e temáticas específicas. Este artigo discute as possibilidades políticas, construídas historicamente, do uso do conceito de cidadania e identifica a alternativa mais propositiva para a postura do profissional de Relações Públicas comprometido e defensor dos pressupostos, idéias e práticas da Comunicação Comunitária.

Palavras-chave: Palavra. Polifonia. Cidadania. Relações públicas comunitárias.
\end{abstract}

\begin{abstract}
While identifying the plurality of meanings contained in a single concept and that such polyphony is an expression of social, political and ideological differences in concrete reality, the etymology of words and their use in specific studies and themes should be clear. The present article discusses political possibilities, historically constructed, of the use of the concept of citizenship and identifies the most comprehensive alternative for the conduct of the Public Relations professional committed to the presuppositions, ideas and actions within the communitarian communication.
\end{abstract}

Keywords: Word. Polyphony. Citizenship. Communitarian public relations.

\section{Introdução}

A escolha das palavras, em nosso cotidiano, é um fenômeno tido como natural e espontâneo, despreocupado dos sentidos políticos contidos nos conceitos, que se mostram plurais.
Metodologicamente, pode-se identificar as palavras como expressão das desigualdades ideológicas da realidade e, assim, reconhecer a necessidade de esclarecimento da historicidade dos conceitos que constituem o universo de termos dos campos de

\footnotetext{
Pós-graduanda em Comunicação Popular e Comunitária na UEL, graduada em Comunicação Social - habilitação em Relações Públicas.

2 Mestre em Comunicação pela Universidade Estadual de Londrina (UEL), graduado em Comunicação Social - habilitação em Relações Públicas (UEL) em atualmente professor do departamento de Comunicação - UEL.
} 
estudo em que atuamos. Com base nessa ideia, é preciso determinar o sentido mais propositivo para nossa atuação.

A problemática da cidadania se apresenta ampla e complexa, pois aglutina diversos sentidos construídos política e historicamente no Brasil. O percurso do conceito perpassa algumas grandes transformações sociais, sobretudo dos contextos liberal, de redemocratização no Brasil e, atualmente, do neoliberalismo. A adaptação da noção de cidadania a cada um desses períodos desloca significativamente seu efeito na sociedade e, conseqüentemente, a atuação política do cidadão.

O conceito de cidadania é plural, desse modo é necessário localizar o sentido mais propositivo dentro dos estudos que compõe a temática de Relações Públicas Comunitárias, com a intenção de defender a atuação do profissional comprometido com a transformação social e emancipação dos cidadãos por meio do estabelecimento das práticas da profissão.

\section{Escolhas Políticas Conscientes no uso das Palavras}

$\mathrm{Na}$ constituição das complexas relações sociais contemporâneas, a linguagem permanece como o instrumento de expressão cognitiva e relacional dos seres humanos, articulando antigas e novas palavras e conceitos em conversas, textos e discursos. Possibilita, dessa maneira, a sistematização de pesquisas e conhecimentos.

A formação das palavras, em uma compreensão puramente semiótica, deu-se com a composição de signos que são possíveis de serem pronunciados pela estrutura física humana e representam (significante) determinado fenômeno da realidade concreta. A utilização das palavras no convívio social inicia o processo de construção dos conceitos e a junção de várias palavras num mesmo processo e identifica a determinação de ideias. (Observação: fonema não é signo, pois é vazio de significado.)
As áreas do conhecimento que se preocupam com o estudo da linguagem e das palavras lidam, quase que exclusivamente, com seus radicais, composição de sintaxe, origem semântica, ou seja, com a palavra em si, em um processo de organização estrutural dos idiomas e de suas respectivas gramáticas. Isolamse importantes componentes na compreensão da realidade, que, por sua vez, é entendida e mediada por meio da linguagem.

Diferentemente das escolas tradicionais, M. Bakhtin, na obra Marxismo e a filosofia da linguagem, preocupou-se com a história das palavras, sua historicidade, com a linguagem em seu uso social. "Isso significa que, no pensamento bakhtiniano, a palavra reposiciona-se em relação às concepções tradicionais, passando a ser encarada como um elemento concreto de feitura ideológica." (BRAIT, 2005, p. 178).

A escolha pelo uso de determinadas palavras em detrimento de outras, demonstra, nessa concepção de linguagem, escolhas ideológicas e defesas políticas determinadas (ou não, considerando-se a condição de alienação) em interação com a realidade viva. Dessa maneira,

\section{[...] a palavra é produto ideológico vivo, funcionando em qualquer situação social (leia-se aqui ideológica), tornando-se signo ideológico porque acumula as entoações do diálogo vivo dos interlocutores com os valores sociais, concentrando em seu bojo as lentas modificações ocorridas na base da sociedade e, ao mesmo tempo, pressionando uma mudança nas estruturas sociais estabelecidas (BRAIT, 2005, p. 178).}

Assim considerada, faz-se preciso entender a interiorização da palavra pelas pessoas e, nesse movimento, entender sua pureza semiótica. Por pureza semiótica, Bakhtin defende que é a capacidade de funcionamento e circulação das palavras enquanto signo neutro em toda e qualquer esfera. É, portanto, neutra em relação a qualquer função ideológica e pode assumir qualquer função ideológica, dependendo do contexto do discurso e enunciado concreto em que aparece. 
Neste sentido, a interiorização concede resposta ao movimento de contato entre o mundo interior dos sujeitos, suas consciências, com o ambiente exterior, ambos construídos cognitivamente por palavras.

Cria-se, neste contexto, uma arena social de disputa pelos sentidos das palavras, visto que um mesmo conceito pode significar posições políticoideológicas contrárias e, no limite, a polifonia de significados nos acomete a necessidade de escolhas a todos os momentos.

Reconhecer a pluralidade de significados contidos num mesmo conceito que expressa, em sua utilização social, as diferenças e desigualdades da realidade concreta, é reconhecer a necessidade de esclarecimento do uso das palavras nas temáticas, assuntos e discursos que assumimos como área de interesse e pesquisa. Isso é feito para que haja condições para a reivindicação de determinadas idéias e conceitos para o estudo.

\section{Cidadania, Conceitos e Contextos}

O conceito de cidadania pode ser entendido de diversas formas, por ter se desenvolvido em diferentes sociedades e processos históricos distintos. Essa origem plural não é, no entanto, a única razão para a diversidade conceitual. Existe, por um lado, uma inocente adaptação do conceito a realidade e, por outro, uma disputa de significados que pode influenciar fortemente o processo de atuação da sociedade civil no Brasil. Buscaremos apresentar aqui a evolução do conceito, delimitar quais as concepções que atualmente disputam espaço no cenário brasileiro e mostrar as consequências de uma despolitização do significado.

Tanto Saes (2001) como Carvalho (2002) colocam Marshall como o primeiro pesquisador a analisar como se desenvolveu a cidadania, bem com a compreender suas dimensões. No contexto do surgimento da sociedade burguesa na Inglaterra, Marshall tenta compreender se todos os indivíduos do país podem ser cidadãos. Para isso, segundo
Pacheco (2001) define que cidadania é um status atribuído a membros de uma comunidade, no caso nacional, por meio do Estado. Esse status de cidadão daria acesso a direitos que não são predefinidos. Porém, como explica Carvalho (2002), Marshall foi capaz de distinguir as naturezas dos direitos que constituem a cidadania, sendo esses os civis, os políticos e os sociais.

Os direitos civis, segundo Carvalho (2001), são aqueles que dizem respeito à vida, à liberdade e à igualdade, como o direito de ir e vir, de expressar opiniões, de se organizar. Estão relacionados, sobretudo, a liberdades individual e ao respeito nas relações entre cidadãos. Já os direitos políticos se referem a participação das pessoas no governo. Porém nem toda população tem acesso a esses direitos, existindo no Brasil, por exemplo, restrições quanto a idade dos eleitores. Não só o voto, como também o direito de organizar e fazer parte de partidos políticos configuram esse grupo. Por fim, os direitos sociais, que devem assegurar a participação da sociedade nos ganhos coletivos de uma nação. Estão inclusos nesse grupo o direito ao trabalho, a saúde, a segurança, educação, entre outros.

É interessante observar que os direitos não estão sempre acompanhados. Direitos sociais podem existir sem direitos políticos, como é o caso, por exemplo, de regimes autoritários, porém paternalistas. A mesma regra não vale para direitos civis. Necessariamente, para se garantir liberdade individual, é preciso que se assegurem, também, direitos políticos. E nem sempre uma nação que possui direitos civis e políticos terá igualdade social, já que isso depende da eficiência do governo, da cobrança da sociedade, entre outros fatores.

Segundo Comparato (1993), a noção dos direitos concedidos a uma comunidade já pôde ser percebida na Grécia. O autor mostra que em Atenas os cidadãos possuíam igualdade de palavra nas assembléias, porém, tinham sua vida privada invadida pelo Estado. Com o surgimento do Estado Liberal, a liberdade é deslocada: passa-se a valorizar 
a liberdade pessoal. O efeito, descrito pelo autor, foi um estado de passividade, no qual a liberdade política de se intervir nas ações de governo fica em segundo plano. Acompanha esse processo a noção de cidadania, definida também como o conjunto de direitos ofertados por uma "comunidade nacional" a seus membros. O termo "nacional" deve ser relevado não só porque os direitos garantidos por Constituição mudam em cada país, mas devido à história política de cada nação, que determina como o conceito de cidadania irá desenvolver-se.

Carvalho (2001) evidencia essas noções, ao comparar a efetivação dos direitos no Brasil e, no caso de Marshall, na Inglaterra que, segundo o autor, foi um processo lento e lógico. Primeiro se concretizaram direitos e liberdade civis, que funcionaram como base para a demanda de direitos políticos que, posteriormente levaram aos direitos sociais. No Brasil, houve uma inversão, na qual os direitos sociais surgiram em detrimento dos direitos políticos, trazidos por um "ditador que se tornou popular" e inibiu liberdades individuais. A esse respeito, o autor conclui que:

O surgimento seqüencial dos direitos sugere que a própria idéia de direitos, e, portanto, a própria cidadania, é um fenômeno histórico. Como havia lógica na seqüência inglesa, uma alteração dessa lógica afeta a natureza da cidadania. Quando falamos de um cidadão inglês, ou norte-americano, e de um cidadão brasileiro, não estamos falando exatamente da mesma coisa. Isto quer dizer que a construção da cidadania tem a ver com a relação das pessoas com o Estado e com a nação. As pessoas se tornavam cidadãs à medida que passavam a se sentir parte de uma nação e de um Estado (CARVALHO, 2001, p. 12).

\section{A Nova Cidadania}

Esse mesmo processo histórico de privação de direitos civis e políticos durante a ditadura militar no Brasil foi responsável por mobilizar um forte conjunto de atores sociais que, no início dos anos 80, utilizavam a noção de cidadania para orientar suas ações políticas. Foi esse momento o responsável por fazer a palavra "cidadania" possuir, no Brasil, uma carga política.
A nova cidadania, ou cidadania ampliada, como explica Dagnino (2004), assume como premissa que é um direito ter direitos, ou seja, que as demandas sociais, civis ou políticas estão em construção e que se concretizam a partir da luta por esses direitos. Essa noção demonstra sobretudo que podem surgir na sociedade novos direitos; que o conjunto de garantias do Estado não é fixo ou imutável.

Mais que isso, a nova cidadania mostra que os cidadãos podem buscar mudanças não só dentro de um sistema delimitado. Quando se pressupõe que os direitos estão sempre em construção, o próprio sistema fica em evidência como passível de mudança. Ohxorn (2010) explica que a sociedade civil pode ser pensada como o conjunto de grupos organizados que coexistem e lutam contra a subordinação ao Estado e a cidadania será o produto dessa interação.

Finalmente, Dagnino (2004) mostra que a cidadania ampliada não acontece somente nas relações institucionais entre Estado e sociedade, mas entre os cidadãos, propondo uma nova forma de "sociabilidade". A cidadania é recolocada, posta em esfera pública, e envolve as relações sociais cotidianas, possibilitando, segundo a autora, o surgimento de uma nova dimensão ética na sociedade. Pacheco (2001) complementa que:

\begin{abstract}
Assim a cidadania, antes de definições jurídicas dos direitos e deveres, é uma identidade social formada a partir de representações e práticas. A busca dessa dimensão simbólica da cidadania no interior da sociedade nos dirá das potencialidades e limites da ação política dos seus membros. Nos dirá das possibilidades de exercício da cidadania no interior desta comunidade política (PACHECO, 2001, p. 11).
\end{abstract}

\section{O Contexto do Conceito de Cidadania do Cenário Neoliberal}

Porém, mais um significado vem ganhando espaço no atual cenário brasileiro. A definição neoliberal de cidadania surge, resgatando alguns aspectos antigos e trazendo alguns novos. Dagnino (2004) explica que, do conceito liberal, retoma a cidadania como um processo que pode existir 
na individualidade. Perde-se concepção de que todo sujeito privado faz parte, inevitavelmente, de uma comunidade. Assim, perde-se o significado de cidadania como ação coletiva passível de ser construída por meio de uma vivência social.

Porém, não é em torno do Estado que a cidadania do contexto neoliberal se concretiza, já que esse está enfraquecido e não tem condições de garantir todos os direitos. Assim surge a relação entre cidadania e mercado, na qual o cidadão pode integrar-se sendo consumidor ou produtor. Oxhorn (2010) aponta ainda que a individualização dos interesses colabora para que exista uma "livre concorrência" dos cidadãos em busca de direitos não mais sociais, e sim privados. Carvalho (2001) aponta que além do enfraquecimento do papel do Estado, a nação deixou de ser a principal identificação dos indivíduos, potencializando assim a visão de mercado: a busca pelo direito do consumo.

O último ponto do deslocamento apontado por Dagnino (2004) é o envolvimento da pobreza à noção de cidadania, não mais por meio da luta por igualdade de direitos, mas sim mediante a solidariedade e a "responsabilidade moral". "A cidadania é identificada com e reduzida à solidariedade para com os pobres, por sua vez, entendida no mais das vezes como mera caridade [...]" (DAGNINO, 2004, p 107).

Pode-se perceber claramente a diferença dos conceitos apresentados e, sobretudo, as implicações de se apropriar esse conceito a uma ação política. A noção da nova cidadania demonstra uma construção coletiva, que empodera os cidadãos frente a realidade. Ainda, evidencia a força da organização social e a consciência política de que os direitos, bem como a sociedade, são (re)feitos a partir do cidadão. $\mathrm{O}$ conceito neoliberal despolitiza a ação social e tira dos indivíduos a responsabilidade de buscar direitos, substituindo-a pela necessidade de adquiri-los. O discurso da solidariedade, por ser perverso por não evidenciar nenhuma forma de transformação social.
De acordo com Dagnino (2004, p. 108),

\begin{abstract}
Esse deslocamento de "cidadania" e "solidariedade" obscurece sua dimensão política e corrói as referências à responsabilidade pública e interesse público, construídas com tanta dificuldade pelas lutas democratizantes do nosso passado recente. A distribuição de serviços e benefícios sociais passa cada vez mais a ocupar o lugar dos direitos e da cidadania, obstruindo não só a demanda por direitos, mas, mais grave, obstando a própria formulação dos direitos e da cidadania e a enunciação da questão pública.
\end{abstract}

\section{A Comunicação no Âmbito dos Conceitos de Cidadania}

O estudo da comunicação, bem como de suas várias interfaces, tem-se tornado cada vez mais relevante para o entendimento dos seres humanos e das relações que esses estabelecem entre si. Por se tratar de um conceito muito abrangente, a comunicação estabelece diálogos efetivos com várias outras áreas das ciências humanas e aplicadas, como por exemplo, as temáticas da cidadania, e os estudos da comunidade e dos movimentos sociais.

Dependente do processo de articulação civil, a cidadania tem como um de seus principais objetivos, assim como a comunicação, gerar participação e envolvimento dos indivíduos de um mesmo contexto. Na sociedade contemporânea, a comunicação e as relações por ela estabelecidas desempenham papel indispensável em âmbito social, espaços e organizações comunitárias.

A comunicação comunitária diz respeito a um processo comunicativo que requer o envolvimento de pessoas de uma "comunidade", não apenas como receptoras de mensagens, mas como protagonistas dos conteúdos e da gestão dos meios de comunicação (PERUZZO apud ESCUDEIRO, 2007, p. 82). Assim como qualquer processo comunicativo, a comunicação a serviço da comunidade deve ser articulada de maneira a estabelecer uma via de mão dupla entre o receptor e o emissor das mensagens, fazendo com que ambos compartilhem da informação e do conhecimento gerado, e, nesse sentido, participem efetivamente do contexto ou realidade em que estejam inseridos. 
O compartilhamento entre os indivíduos permite que a comunicação estabeleça vínculos por meio da participação ativa, o que, em organizações sociais ou de interesse público, mostra-se um fator de extrema importância. De acordo com Kunsch, esse compartilhamento pode ser encarado no próprio trabalho realizado junto à comunidade: "relações públicas comunitárias autênticas são muito mais do que um trabalho 'para' a comunidade, nos moldes tradicionais, por meio de ações sociais, paternalistas", a atividade exige que seja desenvolvido um processo de interação, que possa de fato, estabelecer os vínculos entre os agentes externos, as lideranças e os participantes das organizações comunitárias.

Apenas através desse trabalho de comunicação contínua, será possível articular processos capazes de ampliar o espaço de participação de cada indivíduo, que poderá, dessa forma, contribuir para o desenvolvimento recíproco entre a comunidade, a sociedade e os interesses privados. Nessa perspectiva, as relações públicas, importante área ligada à comunicação, possuem papel fundamental no cumprimento dessa função social e crítica, valorizando processos de emancipação cidadã.

\section{Relações Públicas Comunitárias}

Nessa última década, o avanço da comunicação e das relações públicas acabou por proporcionar um leque de novas possibilidades de atuação e de desenvolvimento, deixando de ser uma prática instrumental e passando a acompanhar a dinâmica da sociedade e de outros grupos, que não apenas os da classe dominante. É nesse sentido que, atualmente, o conceito de relações públicas comunitárias já é considerado de forma concreta e muito utilizado não só em âmbito acadêmico, mas também em toda a atuação profissional.

No Brasil, a preocupação com a função social das relações públicas, apesar de terem sido mencionadas em décadas ainda mais distantes por estudiosos da área, só começou a ganhar espaço de discussão a partir da década de 80, época em que esse campo passou a receber o nome, especificamente, de relações públicas comunitárias. Para Waldemar Luiz Kunsch (2007 a, p. 15), esse conceito é definido como o trabalho realizado por meio do comprometimento com os interesses dos segmentos sociais organizados ou com o interesse público.

Porém, muito antes disso, na década de 70, Teobaldo de Andrade (apud KUNSCH, 2007b) já pregava a necessidade de alinhamento entre os interesses públicos e privados, bem como Harwood Childs (apud KUNSCH, 2007b) que, em 1940, já conceituava as relações púbicas comunitárias, alertando para o que, segundo ele, apresentavase como o principal problema acerca do tema: "o relacionamento de uma organização com a sociedade, cumprindo ela sua missão quando compreende as implicações de uma prática voltada especificamente para esse fim".

Atualmente, muitos são os autores que discutem a respeito das relações públicas comunitárias. Nesse contexto, as relações públicas constituem a atividade de administrar a comunicação nas organizações (KUNSCH, 2007b) por meio de processos efetivos de relacionamento que necessitam do envolvimento e compartilhamento entre indivíduos dos diversos públicos com os quais a organização estabelece relações. Ora, a sociedade e demais organizações sociais são parte fundamental desses públicos, por isso fica claro que as ações das relações públicas podem, igualmente, ser realizadas no contexto das organizações sociais de interesse público (KUNSCH, 2007b).

A partir desse pressuposto, Peruzzo (2011, p. 5) afirma que as relações públicas comunitárias ou populares "são aquelas comprometidas fundamentalmente com a transformação da sociedade e com a constituição da igualdade social". Muitas vezes, as relações públicas em contexto social ou comunitário são confundidas com assistencialismo e suas finalidades definidas 
apenas como arrecadação de verbas, porém ambas as ações que não visam a nenhuma mudança na sociedade, nem transformação de uma realidade ou contexto.

A construção de cada realidade exige que todo e qualquer agente ou sujeito nela inserido participe de forma a atuar, no dia-a-dia, dentro de suas possibilidades e limites, na construção da história, na valorização do coletivo ao individual, criando uma cultura de participação. E, assim, os agentes ou sujeitos irão tornar-se atores sociais, seres-emcomum, cidadãos em seus próprios contextos, atores em sua realidade (PAIVA apud ESCUDEIRO, 2007). A partir dessa reflexão, o profissional de relações públicas deve -se posicionar como parte desse processo e atuar no sentido para colocar-se como sujeito do contexto social, lutando pelos interesses coletivos e pela transformação social, independente do espaço que ocupe profissionalmente.

Peruzzo (2007) afirma, ainda, que as relações públicas comunitárias devem estar comprometidas com a transformação da sociedade: cabe-lhes instituir a igualdade social por meio da comunicação e perceber, assim as características sociais, históricas e culturais do contexto em que atua. A autora afirma que a atividade está ligada ás concepções de mundo e em acreditar no homem e na sua potencialidade de construir uma sociedade justa, nas possibilidades de mudança e, principalmente, em acreditar que as atividades favoreçam a ação coletiva, a partilha do poder de decisão e a co-responsabilidade. Nesse caso, trabalho do profissional é realizado internamente a esse contexto de forma inserida à realidade na qual se trabalha.

$\mathrm{O}$ envolvimento faz com que as atividades ligadas a essa área sejam realizadas de modo cada vez mais distanciado da visão tradicional de ações desenvolvidas 'para' a comunidade (KUNSCH, 2007a), transformando essa visão para um trabalho 'com' a comunidade. Com isso, as relações públicas comunitárias configuram-se a partir do envolvimento e participação ativa dos públicos na transformação de realidade em que estão inseridos.

Para Regina Escudeiro (2007), as relações públicas comunitárias exigem do profissional da área um posicionamento que não esteja restrito apenas aos movimentos sociais periféricos, mas que possa ocorrer em qualquer espaço de atuação. Seja qual for o palco de atuação, as contradições e limitações estão presentes, nessa perspectiva, o profissional responsável e comprometido pode, por meio de suas ações, continuar a preocuparse com questões que envolvam diminuição das desigualdades, e buscar atendendo o interesse público, para a construção de uma sociedade mais igualitária. Por esse motivo, as relações públicas comunitárias possuem papel de grande relevância, pois só assim estarão cumprindo sua função social tão importante de emancipação cidadã.

\section{Considerações Finais}

Ao entendermos que exercer Relações Públicas Comunitárias é mais uma questão de postura comprometida com desenvolvimento da igualdade social e do desenvolvimento de uma sociedade transformada, e menos a ocupação do espaço de relacionamento com uma "comunidade", estamos, implicitamente, desenvolvendo, reivindicando e defendendo um conceito específico de cidadania, que trabalha no sentido de garantir o direito de luta social por melhorias e transformações.

A postura do profissional de Relações Públicas, nesse contexto, necessita do percurso desenvolvido por Bakhtin de reconhecer a polifonia da realidade concreta e que as desigualdades da sociedade brasileira contemporânea são expressas na pluralidade de sentidos dos conceitos, em especial, o conceito de cidadania.

Continuar o exercício profissional sem esse esclarecimento do uso das palavras configuraria uma situação de negligenciamento da realidade e uma continuidade na lógica da alienação, posturas contrárias aos ideais e princípios da comunicação 
comunitária comprometida com a transformação social.

Portanto, a lógica de esclarecimento dos conceitos caros à temática de Relações Públicas Comunitárias, bem como seus caminhos de construção histórica, torna-se-se fundamental para a compreensão da realidade concreta e na atuação exitosa e propositiva do profissional na sociedade, baseada no compromisso social com a "nova cidadania” e a transformação da sociedade.

\section{Referências}

BRAIT, B. Bakhtin: conceitos-chaves. São Paulo: Contexto, 2005.

CARVAlHO, J. M. Cidadania no Brasil: o longo caminho. 3. ed. Rio de Janeiro: Civilização Brasileira, 2002.

Cidadania no Brasil: o longo caminho. Rio de Janeiro:Civilização Brasileira: 2001.

COMPARATO, F. K. A nova cidadania. Lua Nova, São Paulo, n. 28-29, abr. 1993.

DAGNINO, E. ¿Sociedade civil, participação e cidadania: de que estamos falando? In: MATO, Daniel (Coord.). Políticas de ciudadanía y sociedad civil en tiempos de globalización. Caracas: FACES, Universidad Central de Venezuela, 2004. p. 95-110.

ESCUDEIRO, R. C. Movimentos sociais, comunidade e cidadania. In: KUNSCH, Margarida Maria Krohling; KUNSCH Waldemar Luiz (Org.). Relações públicas comunitárias: a comunicação em uma perspectiva dialógica e transformadora. São Paulo: Summus, 2007.

KUNSCH, M. M. K. Dimensões e perspectivas das relações públicas comunitárias. In: KUNSCH, Margarida Maria Krohling; KUNSCH, Waldemar Luiz (Org.). Relações públicas comunitárias: a comunicação em uma perspectiva dialógica e transformadora. São Paulo: Summus, 2007a.

Planejamento estratégico das relações públicas comunitárias. In: KUNSCH, Margarida Maria Krohling; KUNSCH Waldemar Luiz (Org.). Relações públicas comunitárias: a comunicação em uma perspectiva dialógica e transformadora. São Paulo: Summus, 2007b.

OXHORN, P. Cidadania como consumo ou cidadania como agência: uma comparação entre as reformas de democratização da Bolívia e do Brasil. Sociologias, Porto Alegre, v. 12, n. 24, maio/ago. 2010.
PACHECO, R. A. Cidadania e identidade social: uma aproximação teórica para o entendimento das representações e práticas políticas. Mneme Revista de Humanidades, Caicó, v. 2, n. 3, 2001.

PERUZZO, C. M. K. Cidadania, comunicação e desenvolvimento social. In: KUNSCH, Margarida Maria Krohling; KUNSCH Waldemar Luiz (Org.). Relações públicas comunitárias: a comunicação em uma perspectiva dialógica e transformadora. São Paulo: Summus, 2007.

Relações públicas, movimentos populares e transformação social. Disponível em: <http://www. bocc.ubi.pt/pag/peruzzo-cicilia-relacoes-publicas.pdf $>$. Acesso em: 3 abr. 2011.

SAES, D. A. M. A questão da evolução da cidadania política no Brasil. Estudos Avançados, São Paulo, v. 15, n. 24, maio/ago. 2001. 